\title{
Discovery: Under the Microscope at Kennedy Space Center
}

Philip M. Howard

NASA Material Science Division, NE-L6, Kennedy Space Center, Florida 32899 USA

The National Aeronautics \& Space Administration (NASA) is known for discovery, exploration, and advancement of knowledge. Since the days of Leeuwenhoek, microscopy has been at the forefront of discovery and knowledge. No truer is that statement than today at Kennedy Space Center (KSC), where microscopy plays a major role in contamination identification and is an integral part of failure analysis. Space exploration involves flight hardware undergoing rigorous "visually clean" inspections at every step of processing. The unknown contaminants that are discovered on these inspections can directly impact the mission by decreasing performance of sensors and scientific detectors on spacecraft and satellites, acting as micrometeorites, damaging critical sealing surfaces, and causing hazards to the crew of manned missions.

This talk will discuss how microscopy has played a major role in all aspects of space port operations at KSC. Case studies will highlight years of analysis at the Materials Science Division including facility and payload contamination for the Navigation Signal Timing and Ranging Global Positioning Satellites (NAVSTAR GPS) missions, quality control monitoring of monomethyl hydrazine fuel procurement for launch vehicle operations [1], Shuttle Solids Rocket Booster (SRB) foam processing failure analysis, and Space Shuttle Main Engine Cut-off [2] (ECO) flight sensor anomaly analysis.

What I hope to share with my fellow microscopists is some of the excitement of microscopy and how its discoveries has led to hardware processing, that has helped enable the successful launch of vehicles and space flight missions here at Kennedy Space Center.

\section{References}

[1] Howard et al., Characterization of Unique Monomethylhydrazine Non-Volatile Residue, Joint Army Navy NASA Air Force (JANNAF) Interagency Propulsion Committee / $35^{\text {th }}$ Propellant \& Explosives Development and Characterization Subcommittee P\& EDCS 2009

[2] NASA/TM-2009-215567 STS-114 Engine Cut-off Sensor Anomaly Technical Consultation Report 


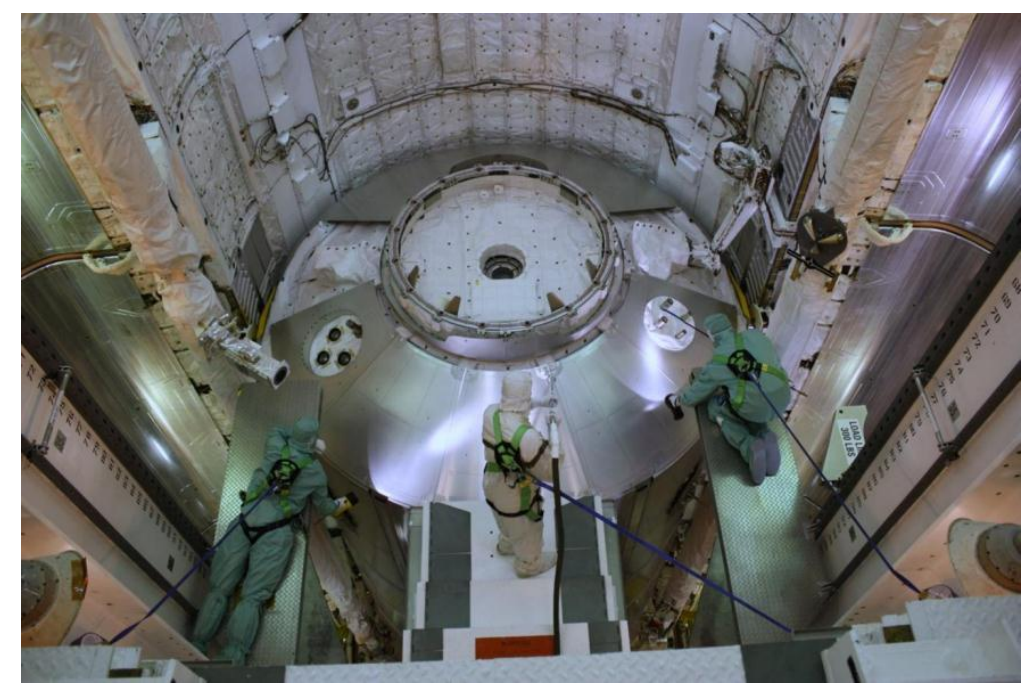

Figure 1. Inspection of Multi-Purpose Logistics Module (MPLM ) at launch pad for the final Space Shuttle STS-135 Mission.
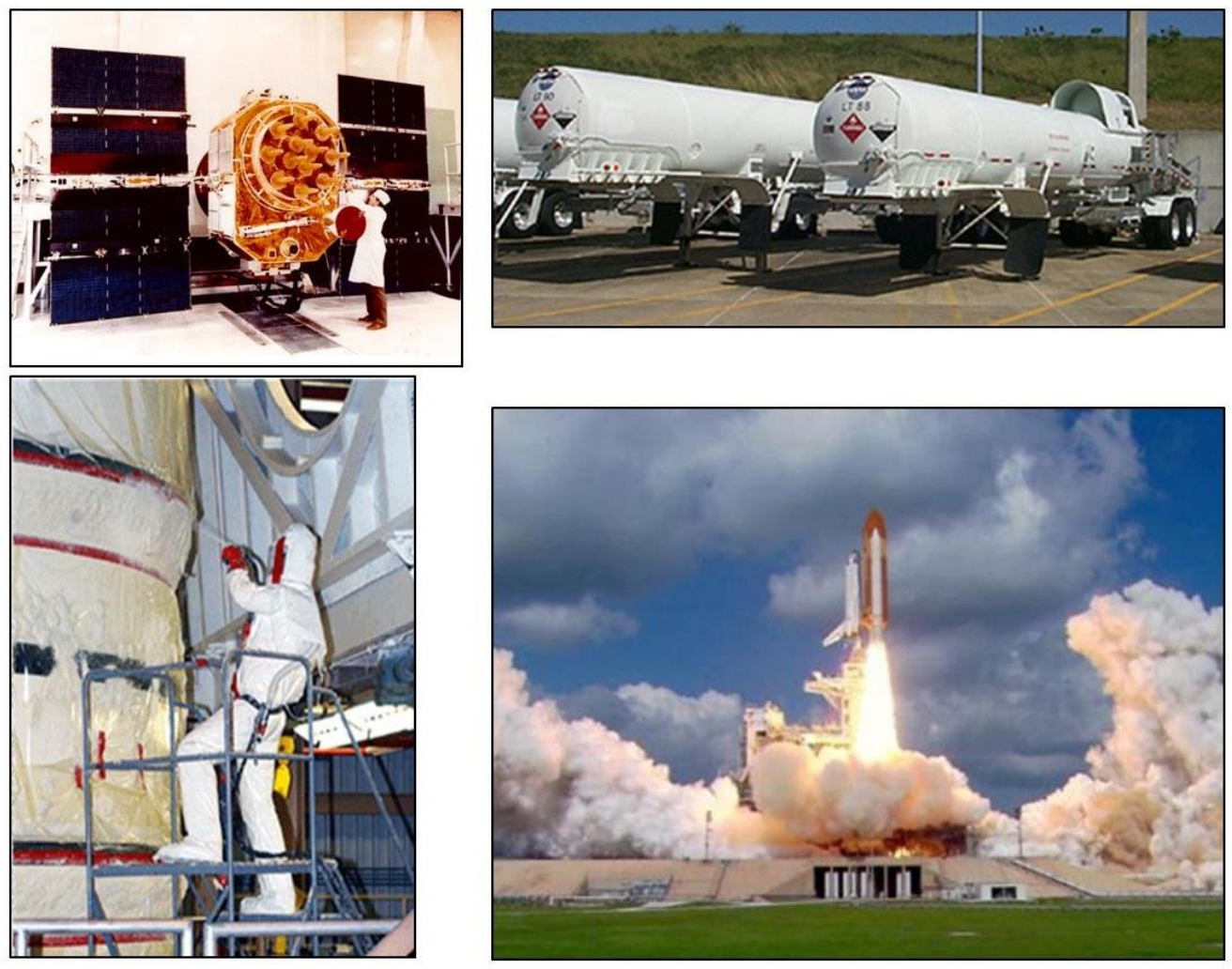

Figure 2. Case studies of facility and satellite processing contamination, commodity procurement, flight hardware processing failure analysis and flight systems anomaly analysis have all contributed to a successful space flight. 